\title{
Automated quantification of fibrosis-related parameters using dual-photon microscopy replace diagnosis of pathologists in NAFLD
}

\author{
Yoshio Sumida ${ }^{1}$, Takeshi Okanoue ${ }^{2}$, Atsushi Nakajima ${ }^{3}$ Japan Study Group of NAFLD (JSG-NAFLD) \\ ${ }^{1}$ Division of Hepatology and Pancreatology, Department of Internal Medicine, Aichi Medical University, Aichi, Karimata, Japan; ${ }^{2}$ Hepatology \\ Center, Saiseikai Suita Hospital, Suita, Osaka, Japan; ${ }^{3}$ Department of Gastroenterology and Hepatology, Yokohama City University, Kanagawa, Japan \\ Correspondence to: Yoshio Sumida. Division of Hepatology and Pancreatology, Department of Internal Medicine, Aichi Medical University, Aichi, \\ Karimata, Japan. Email: sumida19701106@yahoo.co.jp. \\ Comment on: Wang Y, Wong GL, He FP, et al. Quantifying and monitoring fibrosis in non-alcoholic fatty liver disease using dual-photon microscopy. \\ Gut 2020;69:1116-26.
}

Submitted Jan 31, 2020. Accepted for publication Mar 09, 2020.

doi: $10.21037 /$ hbsn.2020.03.23

View this article at: http://dx.doi.org/10.21037/hbsn.2020.03.23

We read with great interest the article by Wong and colleagues (1). Hepatic fibrosis is the most important determinant of mortality in patients with NAFLD (2). Although noninvasive tests or imaging modalities such as FibroScan and MR elastography have been developed for evaluation of hepatic fibrosis (3), liver biopsy is now the gold standard. Liver biopsy has several drawbacks including intra-observers' and inter-observers' variability (4-7), because the histology-based fibrosis is depend on the subjective evaluation by the pathologists. In this article, automated quantification of fibrosis-related parameters (q-FPs) using dual-photon microscopy can accurately diagnose fibrosis stage and predict cumulative incidence of liver-related events (1). It is expected that this novel method will replace diagnosis by pathologists. The strength of this study was based on not only cross-sectional data $(n=344)$ also longitudinal data $(\mathrm{n}=97)$. Limitations in this article exist as authors mentioned. We wonder whether this method can be applied to other ethnic population. An international multi-center trial should be performed for independent external validation. We expect that this novel method can contribute to future clinical trials of NASH drug pipelines for avoiding pathological observers' variabilities.

\section{Acknowledgments}

Funding: None.

\section{Footnote}

Provenance and Peer Review: This article was commissioned by the editorial office of Hepatobiliary Surgery and Nutrition. The article did not undergo external peer review.

Conflicts of Interest: All authors have completed the ICMJE uniform disclosure form (available at http://dx.doi. org/10.21037/hbsn.2020.03.23). The authors have no conflicts of interest to declare.

Ethical Statement: The authors are accountable for all aspects of the work in ensuring that questions related to the accuracy or integrity of any part of the work are 
appropriately investigated and resolved.

Open Access Statement: This is an Open Access article distributed in accordance with the Creative Commons Attribution-NonCommercial-NoDerivs 4.0 International License (CC BY-NC-ND 4.0), which permits the noncommercial replication and distribution of the article with the strict proviso that no changes or edits are made and the original work is properly cited (including links to both the formal publication through the relevant DOI and the license). See: https://creativecommons.org/licenses/by-nc-nd/4.0/.

\section{References}

1. Wang Y, Wong GL, He FP, et al. Quantifying and monitoring fibrosis in non-alcoholic fatty liver disease using dual-photon microscopy. Gut 2020;69:1116-26.

2. Dulai PS, Singh S, Patel J, et al. Increased risk of mortality by fibrosis stage in nonalcoholic fatty liver disease: systematic review and meta-analysis. Hepatology

Cite this article as: Sumida Y, Okanoue T, Nakajima A; Japan Study Group of NAFLD (JSG-NAFLD). Automated quantification of fibrosis-related parameters using dual-photon microscopy replace diagnosis of pathologists in NAFLD. HepatoBiliary Surg Nutr 2020;9(6):815-816. doi: 10.21037/ hbsn.2020.03.23
2017;65:1557-65.

3. Chalasani N, Younossi Z, Lavine JE, et al. The diagnosis and management of nonalcoholic fatty liver disease: Practice guidance from the American Association for the Study of Liver Diseases. Hepatology 2018;67:328-57.

4. Kleiner DE, Brunt EM, Van Natta M, et al. Design and validation of a histological scoring system for nonalcoholic fatty liver disease. Hepatology 2005;41:1313-21.

5. Gawrieh S, Knoedler DM, Saeian K, et al. Effects of interventions on intra- and interobserver agreement on interpretation of nonalcoholic fatty liver disease histology. Ann Diagn Pathol 2011;15:19-24.

6. Fukusato T, Fukushima J, Shiga J, et al. Interobserver variation in the histopathological assessment of nonalcoholic steatohepatitis. Hepatol Res 2005;33:122-7.

7. Merriman RB, Ferrell LD, Patti MG, et al. Correlation of paired liver biopsies in morbidly obese patients with suspected nonalcoholic fatty liver disease. Hepatology 2006;44:874-80. 